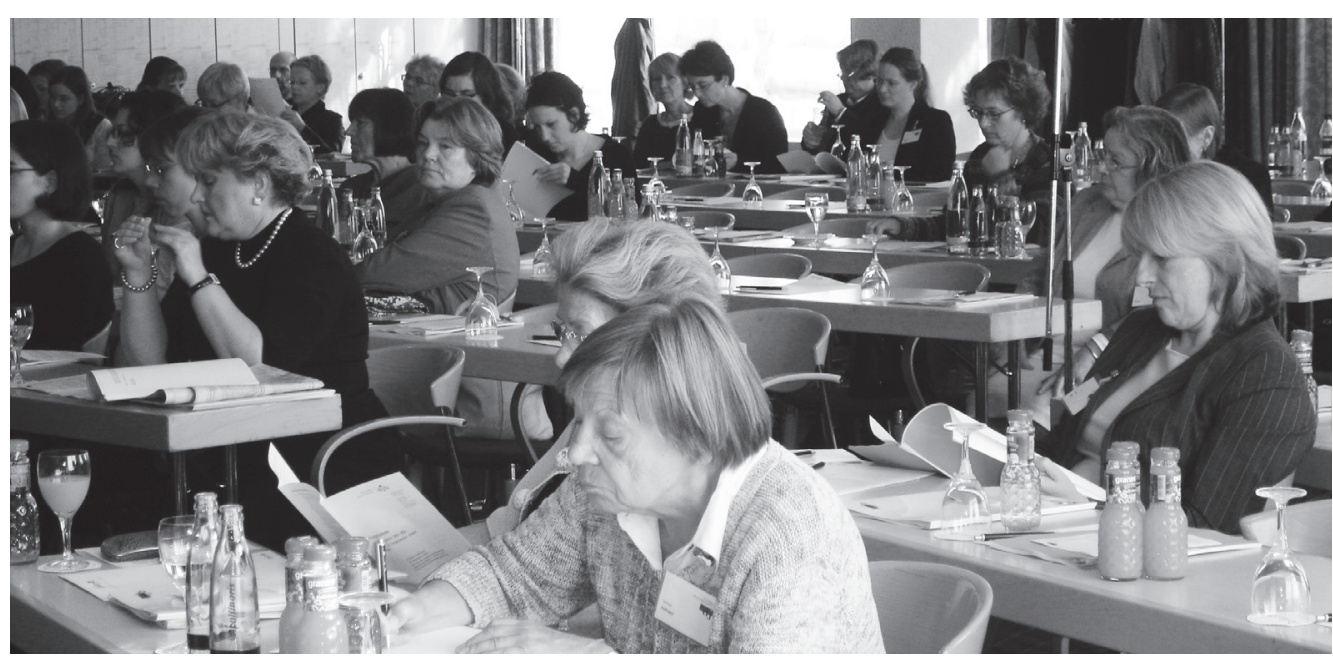

djb-Mitglieder während der Mitgliederversammlung am 22. September 2007 Erfurter Hotel Radisson SAS, im Vordergrund: Gertrud Hofmann, Richterin am OLG München i.R., langjähriges Bundesvorstandsmitglied, Ehrenvorstandsmitglied der djb-RG München-Südbayern. Foto: EH.

\title{
Beitragsordnung des Deutschen Juristinnenbundes
}

beschlossen am 22. September 2007 in Erfurt

\section{\$1 Beitragshöhe}

(1) Die Mitgliederversammlung setzt den Mitgliedsbeitrag fest. Er beträgt 125,00 Euro jährlich.

(2) Mitglieder in der Ausbildung (Studium und Referendariat) zahlen einen ermäßigten Mitgliedsbeitrag in Höhe von 40,00 Euro jährlich.

(3) Auf Antrag wird der Mitgliedsbeitrag auf 60,00 Euro jährlich ermäßigt, wenn

- das Mitglied aus Krankheitsgründen dauerhaft aus dem Erwerbsleben ausgeschieden ist oder

- das 65. Lebensjahr vollendet hat.

(4) Auf Antrag wird der Mitgliedsbeitrag auf 100,00 Euro jährlich ermäßigt, wenn gleichzeitig die Mitgliedschaft in einem Verein oder Verband besteht, der aufgrund der Zugehörigkeit seines Mitglieds zum Deutschen Juristinnenbund ebenfalls eine Ermäßigung gewährt. Die Gegenseitigkeit wird durch Beschluss des Bundesvorstands festgestellt.

(5) Über die Anträge nach $\mathbb{} 1$ Abs. 3 und 4 entscheidet die Schatzmeisterin.

\section{§ 2 Entstehen und Fälligkeit des Mitgliedsbeitrags}

(1) Der Mitgliedsbeitrag entsteht zum 1. Januar eines jeden Jahres. Er ist spätestens bis zum 28. Februar des Jahres zu zahlen, sofern keine Ermächtigung zum Lastschrifteinzug erteilt wurde.

(2) Im ersten Jahr der Mitgliedschaft entsteht kein Mitgliedsbeitrag. Im folgenden Jahr wird der nach $\mathbb{} 1$ fällige Beitrag erhoben. Mitglieder, die am oder nach dem 1. Juli beigetreten sind, zahlen im Folgejahr den halben Beitrag nach $\mathbb{S} 1$.

(3) Die Ehrenmitgliedschaft ist beitragsfrei.

\section{§ 3 Billigkeitsmaßnahmen}

(1) Auf Antrag wird der Mitgliedsbeitrag erlassen, wenn

- das Einkommen des Mitglieds einen Betrag nicht übersteigt, der den Leistungen zur Sicherung des Lebensunterhaltes im Sinne der $\mathbb{S} \mathbb{S} 20$ bis 22 SGB II (Arbeitslosengeld II) entspricht, oder

- das Mitglied eine selbständige, hauptberufliche Tätigkeit aufgenommen hat und deshalb einen Gründungszuschuss gemäß $\$ 57$ SGB III erhält.

Über den Antrag entscheidet die Schatzmeisterin.

(2) In Härtefällen kann der Mitgliedsbeitrag gestundet oder für einen befristeten Zeitraum ganz erlassen werden. Die Gründe für das Vorliegen eines Härtefalles sind in einem Antrag glaubhaft zu machen. Über den Antrag ent- scheiden die Präsidentin und die Schatzmeisterin.

\section{§4 Verfahren bei Beitragsermäßigungen}

(1) Studentinnen werden für 5 Jahre, Referendarinnen für 3 Jahre mit dem ermäßigten Beitrag nach $\mathbb{S} 1$ Abs. 2 geführt. Nach Ablauf dieser Zeit wird automatisch der Beitrag nach $\mathbb{S} 1$ Absatz 1 erhoben, es sei denn, es wird vor Ablauf des Zeitraums, d.h. bis zum 31. Dezember des entsprechenden Jahres, ein Antrag auf Verlängerung gestellt mit der Begründung, dass die Ausbildung noch fortdauert.

(2) Ein Erlass nach $\mathbb{} 3$ Abs. 1 wird grundsätzlich nur für 2 Jahre gewährt. In dem Antrag sind die für die Ermäßigung maßgebenden Tatsachen glaubhaft zu machen (beispielsweise durch Beifügung entsprechender Unterlagen). Nach Ablauf von 2 Jahren wird automatisch der Beitrag nach $\mathbb{S} 1$ Absatz 1 erhoben, es sei denn, es wird vor Ablauf des Zeitraums, d.h. bis zum 31. Dezember des entsprechenden Jahres, ein neuer Antrag auf Beitragsermäßigung gestellt.

\section{§ 5 Inkrafttreten}

Diese Beitragsordnung tritt am 1. Januar 2008 in Kraft. 